\title{
Financial Support for Economic Development Efficiency Research-Based on 13 Cities in Jiangsu Province
}

\author{
Yaocheng Zhuang \\ School of Economics \& Management \\ Nanjing University of Science and Technology \\ Nanjing, China
}

\author{
Lingjie Meng \\ School of Economics \& Management \\ Nanjing University of Science and Technology \\ Nanjing, China
}

\begin{abstract}
Based on the Dea-Bcc method, based on the relevant data of 13 prefecture-level cities in Jiangsu Province from 2010 to 2017 , this paper quantifies the efficiency of financial support for economic development and analyzes it according to the calculation results. The results show that there are differences in different prefecture-level cities.
\end{abstract}

Keywords—financial; DEA; efficiency

\section{INTRODUCTION}

The issue of economic and financial relations has always been the core content of financial research. Especially with the increasing trend of China's economic financialization, the effectiveness of financial resource allocation has greatly affected China's economic efficiency. As we all know, Jiangsu has always been a big economic province. In the second position of the national GDP, what kind of interaction between its own finance and economy, and whether there are differences in the efficiency of financial resource allocation in various regions of the province, these issues are worthy of attention. This article is based on 13 prefecture-level cities in Jiangsu Province 2010-2017 Based on the annual panel data, this paper empirically studies the relationship between financial allocation efficiency and economic development, and uses the Dea-Bcc model to measure the economic development efficiency of 13 cities in Jiangsu Province and conduct objective analysis.

\section{RESEARCh Methods AND Data Processing}

\section{A. DEA Method}

Data Envelopment Analysis is a non-parametric method. The basic idea is to use the evaluation department as the decision-making unit (DMU), using the mathematical programming model to determine the multi-output and multiinput of the decision-making unit, and to determine the optimal production-output frontier, calculate the decisionmaking unit and the optimal. The distance from the production front is used to judge whether the input and output of the decision-making unit are reasonable and effective.

\section{B. Dea-Bcc Model}

The dea-bcc model is one of the traditional dea calculation methods. The scale gain is considered on the basis of the ccr model. The efficiency measure of the bcc model is divided into three efficiencies: comprehensive efficiency, pure technical efficiency and scale efficiency, and the overall efficiency $=$ pure Technical efficiency $*$ Scale efficiency, the results of the effectiveness analysis of the decision-making unit using the bcc model can be explained as follows: When the pure technical efficiency is 1 , the technical state of the decision-making unit is valid; otherwise, the efficiency is invalid, the overall efficiency and the scale efficiency The same applies.

\section{EMPIRICAL ANALYSIS}

\section{A. Indicator Selection and Data Source}

This paper selects 13 cities in Jiangsu Province as the research object, the time span is from 2010 to 2017, the sample data comes from Jiangsu Statistical Yearbook, and dea-solver5.0 is used for empirical research. To compare the financial support economic efficiency of various cities in Jiangsu Province, in the comprehensive after considering the financial economic indicators and the availability of data representing the regional financial input level and output capacity, collect the actual GDP, the tertiary industry added value, the secondary industry added value, the financial institution deposit balance, and the financial institution loan balance and financial institution savings deposit balance data, and corresponding processing to form input and output indicators. Considering that the direct financing market is not mature, the overall scale is small, the degree of data disclosure is not high, and indirect financing based on bank deposits and loans remains. It is the main financing method of each city. Therefore, this paper uses regional deposit banks as the object of measuring local financial resources.

The specific formula is as follows: (See "Table I") 
TABLE I. VARIABLE DEFINITION TABLE

\begin{tabular}{|c|l|l|}
\hline Indicator type & \multicolumn{1}{|c|}{ Indicator name } & \multicolumn{1}{c|}{ Indicator definition } \\
\hline Input indicator & $\begin{array}{l}\text { Financial related ratio } \\
\text { Financial intermediation ratio } \\
\text { Financial savings structure }\end{array}$ & $\begin{array}{l}\text { (Financial institution deposit balance + financial institution } \\
\text { loan balance) / regional gross national product } \\
\text { Financial institution loan balance / financial institution deposit } \\
\text { balance } \\
\text { Financial institution savings deposit balance / financial } \\
\text { institution deposit balance }\end{array}$ \\
\hline Output indicator & $\begin{array}{l}\text { The level of economic development } \\
\text { Industrial structure }\end{array}$ & $\begin{array}{l}\text { Regional gross national product } \\
\text { Third industry added value / second industry added value }\end{array}$ \\
\hline
\end{tabular}

\section{B. Comprehensive Technical Efficiency Analysis}

The DEA-BCC model decomposes the comprehensive technical efficiency of financial support economic development into pure technical efficiency and scale efficiency. Comprehensive technical efficiency measures the efficiency of a bank's financial resources to support economic development, and reflects the minimum input of financial resources under maximum output from an input perspective. When using the DEA model for effectiveness measure, if the overall efficiency of the decision-making unit is 1 , it means that the decision-making unit is in a relatively effective state, achieving maximum output under certain input state or minimizing input under certain output state. (See "Table II")

TABLE II. 2010-2017 COMPREHENSIVE TECHNICAL EFFICIENCY

\begin{tabular}{|c|c|c|c|c|c|c|c|c|}
\hline & 2010 & 2011 & 2012 & 2013 & 2014 & 2015 & 2016 & 2017 \\
\hline Nanjing & 1 & 1 & 1 & 1 & 1 & 1 & 1 & 1 \\
\hline Wuxi & 0.932465 & 0.986127 & 0.949372 & 0.916258 & 0.928752 & 0.920402 & 0.975820 & 1 \\
\hline Xuzhou & 1 & 1 & 1 & 1 & 1 & 1 & 1 & 1 \\
\hline Changzhou & 0.795557 & 0.811852 & 0.815814 & 0.833854 & 0.8567245 & 0.885730 & 0.921576 & 0.945188 \\
\hline Suzhou & 1 & 1 & 1 & 1 & 1 & 1 & 1 & 1 \\
\hline Nantong & 0.861535 & 0.869294 & 0.861080 & 0.860592 & 0.885235 & 0.876948 & 0.940874 & 0.887621 \\
\hline Lianyungang & 1 & 0.995188 & 0.960105 & 0.952127 & 0.872948 & 0.847987 & 0.796382 & 0.824115 \\
\hline Huai'an & 1 & 1 & 1 & 1 & 1 & 1 & 1 & 1 \\
\hline Yancheng & 0.958370 & 0.933303 & 0.900814 & 0.874486 & 0.832628 & 0.845608 & 0.836504 & 0.864706 \\
\hline Yangzhou & 0.778906 & 0.831859 & 0.855630 & 0.845632 & 0.807717 & 0.803452 & 0.809525 & 0.834609 \\
\hline Zhenjiang & 0.821182 & 0.841726 & 0.867079 & 0.868643 & 0.888421 & 0.867838 & 0.839388 & 0.821824 \\
\hline Taizhou & 0.776773 & 0.809768 & 0.790927 & 0.78826 & 0.789557 & 0.801311 & 0.851544 & 0.856365 \\
\hline Suqian & 1 & 0.987021 & 0.934434 & 0.864660 & 0.793679 & 0.724741 & 0.697866 & 0.745887 \\
\hline
\end{tabular}

It can be seen from "Table II" that among the 13 cities in Jiangsu Province, among the cities with comprehensive technical efficiency of 2010-2017 years, there are 6 cities in 2010, namely Nanjing, Xuzhou, Suzhou, Lianyungang, Huai'an and Suqian; There are only four in 2011-2017, and the city has always been four of Nanjing, Xuzhou, Suzhou and Huai'an. The comprehensive technical efficiency of Lianyungang and Suqian has been declining and will only improve in 2017.This shows that the overall efficiency of resource allocation for financial support economic development in Jiangsu Province has not been optimal. The differences between cities and regions have been obvious, and the efficiency of some cities has shown a downward trend. In particular, the trend of Suqian and Lianyungang is obvious, from the initial effective efficiency, invalid, and the efficiency value continues to decline, need to pay attention.

\section{Pure Technical Efficiency Analysis}

The overall efficiency is affected by the efficiency and scale of pure technology. If pure technology and scale efficiency are invalid, the overall efficiency will also be affected. Pure technical efficiency (Vrste) measures the support of financial institutions' business management capabilities, information and technology development. "Table IV" statistics can be made from "Table III". 
TABLE III. 2010-2017 PURE TECHNICAL EFFICIENCY

\begin{tabular}{|c|c|c|c|c|c|c|c|c|}
\hline & $\mathbf{2 0 1 0}$ & $\mathbf{2 0 1 1}$ & $\mathbf{2 0 1 2}$ & $\mathbf{2 0 1 3}$ & $\mathbf{2 0 1 4}$ & $\mathbf{2 0 1 5}$ & $\mathbf{2 0 1 6}$ & $\mathbf{2 0 1 7}$ \\
\hline Nanjing & 1 & 1 & 1 & 1 & 1 & 1 & 1 & 1 \\
\hline Wuxi & 1 & 1 & 1 & 1 & 1 & 1 & 1 & 1 \\
\hline Xuzhou & 1 & 1 & 1 & 1 & 1 & 1 & 1 & 1 \\
\hline Changzhou & 0.965962 & 0.954201 & 0.975586 & 0.982463 & 0.976928 & 0.980587 & 1 & 1 \\
\hline Suzhou & 1 & 1 & 1 & 1 & 1 & 1 & 1 & 1 \\
\hline Nantong & 0.961389 & 0.999352 & 1 & 1 & 1 & 1 & 1 & 0.985238 \\
\hline Lianyungang & 1 & 1 & 1 & 0.997990 & 0.970489 & 0.963984 & 0.940411 & 0.958530 \\
\hline Huai'an & 1 & 1 & 1 & 1 & 1 & 1 & 1 & 1 \\
\hline Yancheng & 0.965642 & 0.948669 & 0.939982 & 0.939935 & 0.945826 & 0.966572 & 0.955985 & 0.957173 \\
\hline Yangzhou & 0.935144 & 0.970569 & 1 & 1 & 1 & 1 & 1 & 0.984283 \\
\hline Zhenjiang & 0.961735 & 0.963055 & 0.989943 & 1 & 1 & 1 & 1 & 0.975339 \\
\hline Taizhou & 0.935493 & 0.926520 & 0.955725 & 0.959804 & 0.955331 & 0.949443 & 0.975091 & 0.955094 \\
\hline Suqian & 1 & 1 & 1 & 1 & 0.987568 & 0.957382 & 0.964733 & 0.972224 \\
\hline
\end{tabular}

TABLE IV. 2010-2017 PuRE TeChNicAL EFFICIENCY VALUE Is Quantity

\begin{tabular}{|c|c|c|c|c|c|c|c|c|}
\hline Years & $\mathbf{2 0 1 0}$ & $\mathbf{2 0 1 1}$ & $\mathbf{2 0 1 2}$ & $\mathbf{2 0 1 3}$ & $\mathbf{2 0 1 4}$ & $\mathbf{2 0 1 5}$ & $\mathbf{2 0 1 6}$ & $\mathbf{2 0 1 7}$ \\
\hline Quantity & 7 & 7 & 9 & 9 & 8 & 8 & 9 & 6 \\
\hline
\end{tabular}

In terms of pure technical efficiency, the business management capabilities of financial institutions in 13 cities in Jiangsu Province need to be improved. More than onethird of the 13 cities in the city still have purely technical efficiency, and these regions have no resources to invest in the economic development process. Reasonable and inefficient use of resources, the use of resources is not achieved, and the efficiency can be optimized by introducing technology and rationally allocating resources. The pure technical efficiency values of the five cities of Nanjing,
Wuxi, Suzhou, Xuzhou and Huai'an in the 13 cities have been 1 , which is effective efficiency. Compared with the comprehensive efficiency of "Table II", Nanjing, Xuzhou, Suzhou, and Huai'an have comprehensive efficiency and pure technical efficiency, and the efficiency value has been 1 in 2010-2017, which has achieved financial support for economic development. On the basis of realizing pure and efficient technology, Wuxi City has comprehensive efficiency and is not effective. Its scale efficiency is not effective and can be improved.

TABLE V. 2010-2017 SCALE EFFICIENCY

\begin{tabular}{|c|l|l|l|l|l|l|l|l|}
\hline & \multicolumn{1}{|c|}{$\mathbf{2 0 1 0}$} & \multicolumn{1}{|c|}{$\mathbf{2 0 1 1}$} & \multicolumn{1}{|c|}{$\mathbf{2 0 1 2}$} & $\mathbf{2 0 1 3}$ & $\mathbf{2 0 1 4}$ & $\mathbf{2 0 1 5}$ & $\mathbf{2 0 1 6}$ & $\mathbf{2 0 1 7}$ \\
\hline Nanjing & 1 & 1 & 1 & 1 & 1 & 1 & 1 & 1 \\
\hline Wuxi & 0.932460 & 0.986127 & 0.94937 & 0.916258 & 0.928752 & 0.920402 & 0.975820 & 1 \\
\hline Xuzhou & 1 & 1 & 1 & 1 & 1 & 1 & 1 & 1 \\
\hline Changzhou & 0.823590 & 0.850810 & 0.836220 & 0.84874 & 0.876958 & 0.903265 & 0.921576 & 0.945188 \\
\hline Suzhou & 1 & 1 & 1 & 1 & 1 & 1 & 1 & 1 \\
\hline Nantong & 0.896135 & 0.869857 & 0.861080 & 0.860592 & 0.885235 & 0.876948 & 0.940874 & 0.900921 \\
\hline Lianyungang & 1 & 0.995188 & 0.960100 & 0.954045 & 0.899493 & 0.879669 & 0.846844 & 0.859770 \\
\hline Huai'an & 1 & 1 & 1 & 1 & 1 & 1 & 1 & 1 \\
\hline Yancheng & 0.992468 & 0.983803 & 0.958330 & 0.930368 & 0.880318 & 0.874852 & 0.875018 & 0.903396 \\
\hline Yangzhou & 0.832926 & 0.857083 & 0.855620 & 0.845632 & 0.807717 & 0.803452 & 0.809525 & 0.847936 \\
\hline Zhenjiang & 0.853854 & 0.874017 & 0.875880 & 0.868643 & 0.888421 & 0.867838 & 0.839388 & 0.842600 \\
\hline Taizhou & 0.830335 & 0.873988 & 0.827560 & 0.821273 & 0.826474 & 0.843979 & 0.873297 & 0.896629 \\
\hline Suqian & 1 & 0.987021 & 0.934430 & 0.864660 & 0.803670 & 0.757000 & 0.723377 & 0.767196 \\
\hline average & 0.935521 & 0.944450 & 0.927580 & 0.916169 & 0.907460 & 0.902108 & 0.908130 & 0.920280 \\
\hline
\end{tabular}

\section{Scale Efficiency Analysis}

Scale efficiency measures the strength of financial institutions' investment in the real economy and whether it is at the optimal scale. According to "Table V", except for the scale efficiency of Nanjing, Xuzhou, Suzhou and Huai'an, the scale efficiency of Wuxi and Yancheng has remained above 0.9.From the perspective of the trend of change, the scale efficiency value of Lianyungang and Suqian has shown a downward trend, which is consistent with the conclusions of the previous comprehensive technical efficiency and pure technical efficiency. The overall technical efficiency of Suqian and Lianyungang shows a downward trend, mainly due to the scale. The decline in efficiency has caused the scale of funds invested by financial institutions to be nonoptimal. 


\section{CONCLUSIONS AND RECOMMENDATIONS}

\section{A. Conclusions}

Combined with the full text, we can draw the following conclusions:

The average comprehensive technical efficiency and scale efficiency of financial support economic development in 13 cities in Jiangsu Province are relatively high, and the average value of pure technical efficiency is close to the effective state, indicating that the management level of financial institutions in Jiangsu Province is relatively high, and business management innovation is on economic growth. Play a positive role.

There is a difference in the role and efficiency of financial support in different prefecture-level cities. The financial support economic development efficiency among the 13 prefecture-level cities is obviously different. It is necessary to adjust the specific conditions of each level-level city to achieve the best efficiency.

Nanjing, Suzhou, Xuzhou and Huai'an four cities, since 2010-2017, financial support for economic growth has been in an effective state, which has contributed greatly to economic growth, and GDP in Jiangsu Province. The city ranking is inseparable. In addition, the financial support economic development efficiency of Lianyungang City and Suqian City is relatively low, and the efficiency value is relatively decreasing, which needs to be paid attention to.

\section{B. Recommendations}

First, focus on reform and innovation, attract financial resources to serve the real economy.

Coordinating and coordinating policy banks, joint-stock commercial banks and local financial institutions in their respective jurisdictions to give full play to their respective advantages and to further promote financial reform and innovation in key areas. Serve and support the economic development strategy of Jiangsu Province, take this as an opportunity to meet the financial needs of industrial transfer and undertaking, technology transformation, and strive to make breakthroughs in financial service reform and innovation; support financial development and actively innovate financial products and services, Financial support is provided for economic development.

Second, implementing a prudent monetary policy and guiding the steady and moderate growth of credit supply.

Guide banking financial institutions to ensure that the total amount of credit is in line with the development needs of the province's real economy in accordance with the requirements of sound neutral monetary policy and macroprudential policy, and the rhythm of the delivery is linked to the operating rhythm of the real economy, and steadily and appropriately increase credit supply. To meet the effective credit demand of the real economy; optimize the credit structure of financial institutions, standardize inter-bank business and transfer discounted business, curb "de-reality", reduce internal leverage, improve the efficiency and level of serving the real economy; Financial services play an important role in financial support for economic development.

\section{REFERENCES}

[1] Goldsmith R W. Financial Structure and Development [M]. New Haven:Yale University Press, 1969.

[2] Ronald I.Mc Kinnon. Money and Capital in Economic Development [M]. Washington DC: Brookings institution Press, 1973:58-72.

[3] Li Qiang, Xu Kangning. Financial Development, Real Economy and Economic Growth: Empirical Analysis Based on Provincial Panel Data [J]. Shanghai Economic Research, 2013, (9): 3-10.

[4] Li Xueqin, Fang Xianming. Analysis of Regional Economic Development Imbalance under the Perspective of Financial Support [J]. Shanghai Finance. 2010,(6):22-25。

[5] Jiang Zhitao. Research on the Efficiency of Financial Support for the Development of Real Economy - Based on Provincial Panel Data [D]. Anhui University Master Thesis, 2014.

[6] Song Yanwei, Li Hengqi. Research on the Relationship between Regional Financial Development and Economic Growth in China [J]. Statistics and Decision-making, 2007, (6):73-78.

[7] Sun Aijun, Jiang Wei, Fang Xianming. Comparison of Financial Support Economic Development Efficiency [J]. Journal of Central University of Finance and Economics, 2011, (11): 34-39.

[8] Wang Zhiqiang, Sun Gang. Empirical Analysis of the Relationship between Scale, Structure, Efficiency and Economic Growth of China's Financial Development [J]. Management World, 2003, (7): 13-20.

[9] Wang Shuhua, Fang Xianming. Financial Support and Regional Financial Development: An Empirical Study of Opportunity Jiangsu Data [J]. Statistics and Decision Making, 2006, (9): 81-84.

[10] Zhao Weiguang, Jing Li. Total Factor Productivity, Capital Investment and Economic Growth in the Five Northwestern Provinces [J]. Technology and Industry, 2015, (2): 17-23. 